\title{
Innovative Multi-Feed-Per-Beam Reflector Antenna for Space-Borne Conical-Scan Radiometers
}

de Lasson, Jakob R.; Cappelin, Cecilia ; Pontoppidan, Knud; lupikov, Oleg; Ivashina, Marianna; Skou, Niels; Fiorelli, Benedetta

\section{Published in:}

2018 leee International Symposium on Antennas and Propagation and Usnc/ursi National Radio Science Meeting

Link to article, DOI:

10.1109/APUSNCURSINRSM.2018.8609321

Publication date:

2019

Document Version

Peer reviewed version

Link back to DTU Orbit

Citation $(A P A)$ :

de Lasson, J. R., Cappelin, C., Pontoppidan, K., lupikov, O., Ivashina, M., Skou, N., \& Fiorelli, B. (2019). Innovative Multi-Feed-Per-Beam Reflector Antenna for Space-Borne Conical-Scan Radiometers. In 2018 leee International Symposium on Antennas and Propagation and Usnc/ursi National Radio Science Meeting (pp. 1729-1730). IEEE. https://doi.org/10.1109/APUSNCURSINRSM.2018.8609321

\section{General rights}

Copyright and moral rights for the publications made accessible in the public portal are retained by the authors and/or other copyright owners and it is a condition of accessing publications that users recognise and abide by the legal requirements associated with these rights.

- Users may download and print one copy of any publication from the public portal for the purpose of private study or research.

- You may not further distribute the material or use it for any profit-making activity or commercial gain

- You may freely distribute the URL identifying the publication in the public portal 


\section{Innovative Multi-Feed-Per-Beam Reflector Antenna for Space-Borne Conical-Scan Radiometers}

\author{
Jakob R. de Lasson, \\ Cecilia Cappellin, \\ and Knud Pontoppidan \\ TICRA \\ Copenhagen, Denmark \\ jrdl@ticra.com
}

\author{
Oleg Iupikov \\ and Marianna Ivashina \\ Chalmers University of Technology, \\ Gothenburg, Sweden \\ marianna.ivashina@chalmers.se
}

\author{
Niels Skou
}

DTU Space,

Kgs. Lyngby, Denmark

ns@space.dtu.dk
Benedetta Fiorelli

ESA-ESTEC

Noordwijk, The Netherlands

Benedetta.Fiorelli@esa.int

\begin{abstract}
We present an antenna for use on conical-scan space-borne radiometers in $\mathrm{C}$ band and demonstrate that stringent radiometric requirements can be met. The antenna consists of a $5 \mathrm{~m}$ offset reflector fed by a focal plane array in a multi-feedper-beam configuration, so far never used in ocean observation missions. We use distinct element beams and two optimization routines for obtaining element excitation amplitudes and phases, and with either routine, and in both $x$ - and $y$-polarization, compliant beams, with footprint $<20 \mathbf{k m}$, distance to coast $<20$ $\mathbf{k m}$ and accuracy $<0.25 \mathbf{K}$, are obtained. These results may pave the way for use of focal plane arrays with digital beamforming in future radiometric ocean observation missions.
\end{abstract}

\section{INTRODUCTION}

Microwave radiometers are remote sensors that can measure a multitude of properties of the atmosphere and oceans, including, for example, the ocean surface wind vector and sea surface temperature [1]. Important characteristics of radiometers for ocean observation include spatial resolution (also known as footprint), accuracy, radiometric resolution and distance to coast, the last one quantifying how close to land and sea ice the radiometer can accurately measure. The radiometric requirements can be converted into antenna specifications, and the spatial and radiometric resolutions can be controlled by the reflector size and the number of beams produced by the antenna, respectively [2]. In contrast, accuracy and distance to coast depend on a low cross-polar field (high polarization purity) and low sidelobes, respectively, quantities that inherently depend on properties of the feed.

Stringent requirements for future ocean observation radiometers, for example requiring a distance to coast of $<20$ $\mathrm{km}$ and an accuracy of $<0.25 \mathrm{~K}$ in $\mathrm{C}$ band, cannot be fulfilled with conventional single-feed-per-beam [1], but can with feed arrays of closely-spaced, $<0.75 \lambda$-sized elements in multifeed-per-beam configurations. In these, more elements take part in the formation of each beam, and the same element takes part in the formation of multiple beams, realized via optimization and a digital beamformer [1]-[4]. For a conicalscan radiometer in $\mathrm{C}$ band, two so-called along-track beams are required [3]. Here, we present how these two beams can be generated by an offset reflector fed by a focal plane array of 67 properly excited Vivaldi elements [1]. As a novelty of this work, we here, as opposed to the procedure used previously [2], do not assume identical element beams, but instead include mutual element coupling and the effect from edge truncation and use distinct patterns for each element.

\section{REFLECTOR ANTENNA AND ViVALDI ARRAY}

We consider an offset parabolic reflector with (projected) aperture diameter of $D=5 \mathrm{~m}$, focal length of $f=3 \mathrm{~m}$ and clearance of $d^{\prime}=1 \mathrm{~m}$. The reflector is fed by an array of $35 x$-oriented and $32 y$-oriented Vivaldi elements on top of a finite-size ground plane. The full antenna is illustrated in Figure 1, including a zoom of the Vivaldi array. We use the MoM/MLFMM add-on to the GRASP software [5] and take mutual coupling between the elements and the finite size of the ground plane into account. Details of the array as well as simulated and measured element patterns can be found in [1].



Fig. 1. Radiometer antenna consisting of an offset reflector $(D=5 \mathrm{~m})$ fed by an array of $35 x$-oriented and $32 y$-oriented Vivaldi elements on top of a finite-size ground plane. The inset shows a zoom of the Vivaldi array.

\section{CONICAL-SCAN RADIOMETER BEAMS}

Using the (secondary) element patterns as input, we have used two different optimization routines, referred to as Optimization A [2] and B [4], to determine the 67 element excitation coefficients that produce the two required beams. 
TABLE I

CHARACTERISTICS OF $x$ - AND $y$-POLARIZED BEAMS PRODUCED By THE ANTENNA IN FIGURE 1.

\begin{tabular}{|c|c|c|c|c|c|c|c|c|c|}
\hline & & \multicolumn{4}{|c|}{ Optimization A [2] } & \multicolumn{4}{|c|}{ Optimization B [4] } \\
\hline & & \multicolumn{2}{|c|}{$x$-pol. } & \multicolumn{2}{|c|}{$y$-pol. } & \multicolumn{2}{|c|}{$x$-pol. } & \multicolumn{2}{|c|}{$y$-pol. } \\
\hline & Goal & Upper & Lower & Upper & Lower & Upper & Lower & Upper & Lower \\
\hline Cross-polar power [\%] & $<0.29$ & 0.19 & 0.17 & 0.07 & 0.08 & 0.14 & 0.15 & 0.08 & 0.12 \\
\hline Footprint $[\mathrm{km}]$ & $<20$ & 19.7 & 19.6 & 19.9 & 19.7 & 19.0 & 19.0 & 19.0 & 19.0 \\
\hline Distance to coast $[\mathrm{km}]$ & $<20$ & 12.8 & 16.2 & 17.2 & 15.9 & 14.6 & 12.4 & 12.4 & 14.5 \\
\hline Beam overlap [\%] & $\sim 30$ & & & & & & & & \\
\hline
\end{tabular}

Antenna pattern and radiometer characteristics of the beams are collected in Table I. Comparing to the requirements (second column), it is apparent that all four beams, with either of the optimization routines, are compliant, which is promising for use of focal plane arrays in future ocean observation missions. We also remark that all radiometer characteristics are similar among the two optimization routines.

As an example, Figure 2 displays the far-field directivity of the $x$-polarized lower beam, with $-3 \mathrm{~dB}$ contours of the upper and lower beams overlaid (from Optimization A). Figure 3 displays amplitudes of element excitation coefficients producing the lower beam, with the top (bottom) panel showing coefficients for the $35 x$-oriented (32 $y$-oriented) Vivaldi elements. As expected due to the choice of polarization, the $x$ oriented elements dominate, and elements towards the center of the array are excited the most, with a slight asymmetry along the long axis of the array stemming from the offset nature of the antenna as well as from the scan of the beam. Each element beam gives rise to a non-negligible cross-polar far field [1], and we interpret the small excitation of (especially the central) $y$-oriented elements as a means to cancel as much as possible the relative cross-polar power of the beams.

In this study, we have used Vivaldi elements, but we stress that other closely-spaced elements can be used and give similar performance [2], and that the concept presented here can be applied to pushbroom radiometers as well [3].

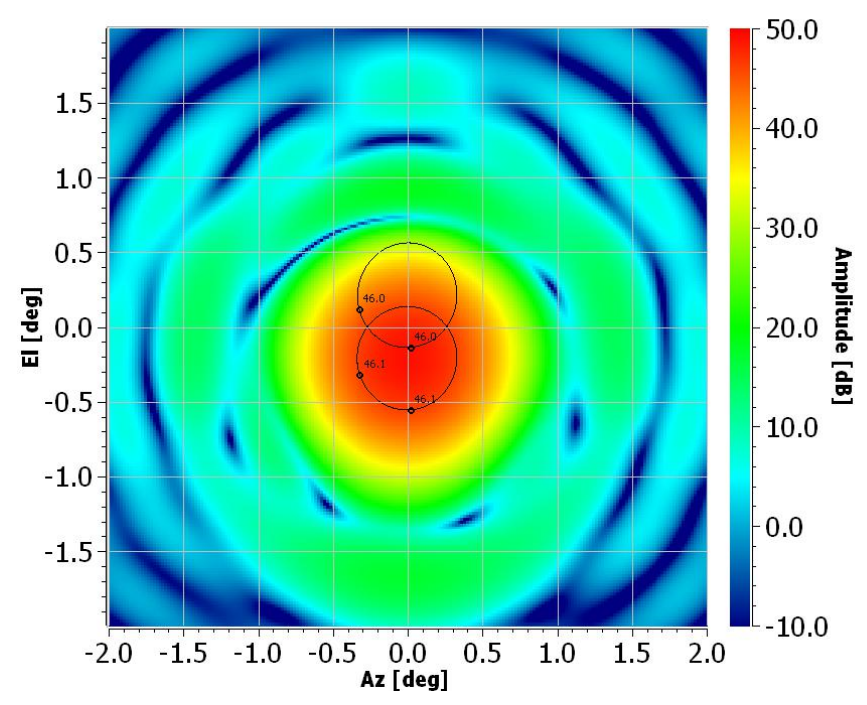

Fig. 2. Far-field directivity of $x$-polarized lower beam. $-3 \mathrm{~dB}$ contours of the upper and lower beams are overlaid. Results from Optimization A.
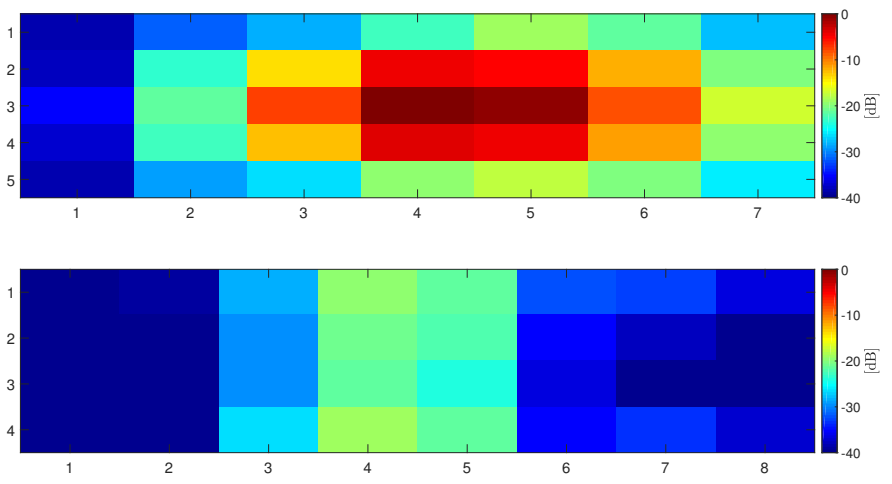

Fig. 3. Amplitudes of element excitation coefficients producing the $x$ polarized lower beam shown in Figure 2. Top: $35 x$-oriented Vivaldi element amplitudes. Bottom: 32 y-oriented Vivaldi element amplitudes.

\section{CONCLUSiON}

We have presented an antenna for use on a conical-scan space-borne radiometer and demonstrated that this antenna produces beams compliant with stringent requirements for future ocean observation missions. The antenna consists of a $D=5 \mathrm{~m}$ offset reflector fed by a focal plane array of 67 closely-spaced Vivaldi elements in a multi-feed-perbeam configuration. We have used distinct element patterns, including mutual coupling and edge truncation, and two different element excitation routines to generate the two beams needed in $\mathrm{C}$ band, and in both $x$ - and $y$-polarization, and with either optimization routine, obtained compliant beams, with a distance to coast $<20 \mathrm{~km}$ and a relative cross-polar power $<0.29 \%$ (accuracy $<0.25 \mathrm{~K}$ ). These results may open up for use of multi-feed-per-beam antennas in radiometric ocean observation missions, where measuring close to land and ice with very high resolution and polarization purity is required.

\section{REFERENCES}

[1] C. Cappellin, J. R. de Lasson, O. Iupikov, M. Ivashina, N. Skou, K. Pontoppidan, and B. Fiorelli, "Feed array breadboard for future passive microwave radiometer antennas," in 12th European Conference on Antennas and Propagation (EuCAP), April 2018.

[2] O. Iupikov, M. Ivashina, N. Skou, C. Cappellin, K. Pontoppidan, and K. van 't Klooster, "Multi-beam focal plane arrays with digital beamforming for high precision space-borne ocean remote sensing," IEEE Transactions on Antennas and Propagation, 2018, in press.

[3] C. Cappellin, K. Pontoppidan, P. Nielsen, N. Skou, S. Søbjærg, M. Ivashina, O. Iupikov, A. Ihle, D. Hartmann, and K. van 't Klooster, "Novel multi-beam radiometers for accurate ocean surveillance," in 8th European Conference on Antennas and Propagation (EuCAP). IEEE, 2014, pp. 3531-3535.

[4] O. Iupikov, "Digital beamforming focal plane arrays for radio astronomy and space-borne passive remote sensing," Ph.D. dissertation, Chalmers University of Technology, Department of Electrical Engineering, 2017.

[5] GRASP Software, TICRA, Copenhagen, Denmark, www.ticra.com. 